\title{
1 Relationships between pond water and tilapia skin microbiomes in 2 aquaculture ponds in Malawi
}

Jamie McMurtrie ${ }^{1,2 \#^{*}}$, Shayma Alathari ${ }^{1,2^{*}}$, Dominique L. Chaput ${ }^{1}$, David Bass ${ }^{2,3,4}$, Camerson Ghambi $^{5}$, Joseph Nagoli ${ }^{6}$, Jérôme Delamare-Deboutteville ${ }^{7}$, Chadag Vishnumurthy Mohan ${ }^{7}$, Joanne Cable ${ }^{8}$, Ben Temperton ${ }^{1}$, Charles R. Tyler ${ }^{1,2}$

${ }^{1}$ Biosciences, Geoffrey Pope Building, University of Exeter, Exeter, Devon EX4 4HB, UK

${ }^{2}$ Sustainable Aquaculture Futures, University of Exeter, Exeter, Devon EX4 4QD, UK

${ }^{3}$ Centre for Environment, Fisheries and Aquaculture Science (CEFAS), Weymouth Laboratory, Weymouth, Dorset DT4 8UB, UK

${ }^{4}$ Department of Life Sciences, The Natural History Museum, Cromwell Rd, London, SW7 $5 \mathrm{BD}, \mathrm{UK}$

${ }^{5}$ Department of Aquaculture and Fisheries Science, Lilongwe University of Agriculture and Natural Resources (LUANAR), P.O. Box 219, Lilongwe, Malawi

${ }^{6}$ WorldFish Malawi, Lilongwe, P.O. Box 30294, Malawi

${ }^{7}$ WorldFish, Bayan Lepas, Penang, Malaysia

${ }^{8}$ School of Biosciences, Cardiff University, Cardiff, CF10 3AX

\# Correspondence: (JM) jm1106@ exeter.ac.uk +44-(0)-1392-724677

* JM and SA listed as co-first authors

\section{Highlights}

- Tilapia skin communities vary in different ponds but share some common taxa

- Pond sites have a stronger influence on water microbiome community structure than in fish skin

- Selected skin-associated taxa could be used to monitor dysbiotic events

- The fish skin microeukaryotic community is complex and poorly characterised

\section{Abstract}

Intensification of fish farming practices is being driven by the demand for increased food production to support a rapidly growing global human population, particularly in lower-middle income countries. Intensification of production, however, increases the risk of disease outbreaks and thus likelihood for crop losses. The microbial communities that colonise the skin mucosal surface of fish are poorly understood, but are important in maintaining fish health and resistance against disease. This skin microbial community is susceptible to disruption through stressors associated with transport, handling and the environment of intensive practices, and this risks the propagation of disease-causing pathogens. In this study, we characterised the microbial assemblages found on tilapia skin - the most widely farmed finfish globally — and in the surrounding water of seven earthen aquaculture ponds from two pond systems in distinct geographic regions in Malawi. Metabarcoding approaches were used to sequence the prokaryotic and microeukaryotic communities. We found $92 \%$ of prokaryotic amplicon sequence variants were common to both skin and water samples. Differentially enriched and core taxa, however, differed between the skin and water samples. In tilapia skin, Cetobacterium, Paucibacter, Pseudomonas and Comamonadaceae were enriched, whereas, the cyanobacteria Cyanobium, Microcystis and/or Synechocystis, and the diatom Cyclotella, were most prevalent in pond water. Ponds that clustered together according to their water prokaryotic communities also had similar microeukaryotic communities indicating strong environmental influences on prokaryotic and microeukaryotic community structures. While strong sitespecific clustering was observed in pond water, the grouping of tilapia skin prokaryotes by 
pond site was less distinct, suggesting fish microbiota have a greater buffering capacity against environmental influences. The characterised diversity, structure and variance of microbial communities associated with tilapia culture in Malawi provides the baseline for studies on how future intensification practices may lead to microbial dysbiosis and disease onset.

Keywords

Aquaculture, skin microbiome, tilapia, pond, bacterial community, eukaryotic community

\section{Introduction}

Capture fisheries will not be able to satisfy the demand for seafood products from an everincreasing human population with rising living standards (Henchion et al., 2017) combined with plateauing, and in some cases declining, wild fish stocks due to overfishing and ecosystem degradation (Link and Watson, 2019). Seeking to meet this demand for aquatic products, many aquaculture farming practices are undergoing intensification. Shifting from extensive to intensive and semi-intensive practices in aquaculture however, is often associated with increased incidence of infectious disease (Hinchliffe et al., 2020; Pulkkinen et al., 2010). Intensification can cause chronic stress that adversely impacts fish physiology resulting in reduced growth and impaired disease resilience. Increasing pond stocking rates and/or levels often occurs with insufficient amounts of clean water, leading to the deterioration of water quality, including for dissolved oxygen, $\mathrm{pH}$ and ammonia (Abdel-Tawwab et al., 2014; Sundh et al., 2019), which in turn also impacts negatively on fish growth and health, and renders the fish more susceptible to diseases. Regular restocking of ponds with fish of uncertain health status to compensate for mortalities, in turn, increases the likelihood of repeated introductions of sub-clinical infections (Bondad-Reantaso et al., 2005; Murray and Peeler, 2005).

Disease remains a huge challenge for aquaculture, particularly in Asia where $89 \%$ of global aquaculture production occurs (FAO, 2020c). Successful management of disease risk and intensification of production of aquatic species requires a better understanding of the relationships between the microbial systems (microbiomes) in the environments in which they are grown and on/in the organisms cultured (Bass et al., 2019). The study of microbiomes in aquaculture is gaining momentum and recent studies have investigated how pond and fish treatments (e.g. antibiotics, dietary supplements, probiotic treatments and pond fertilisers) affect fish microbiomes (Limbu et al., 2018; Minich et al., 2018; Suphoronski et al., 2019; Tan et al., 2019). Much of this research has focused on the gut microbiome due to its intricate role in gut health, which when optimised can maximise feed conversion, growth, and overall aquaculture productivity (Perry et al., 2020). When considering disease resistance and/or susceptibility in fish aquaculture however, arguably the microbial communities harboured on/in the skin and gill are likely to be equally if not more important.

These outer facing mucosal surfaces are in continuous contact with the aquatic environment and provide a primary barrier against invading pathogens (Legrand et al., 2018; Rosado et al., 2019b). The microbes colonising this skin niche include those specifically adapted to the host mucosal surface, as evidenced by host-species specificity of microbiome composition (Doane et al., 2020), but also microbes derived from the surrounding water community (Krotman et al., 2020). Relatively little is known about the environmental and host contributions to these microbial assemblages, particularly in aquaculture ponds. It is known, however, that skin colonisers have a direct connection with the host immune system helping to shape its function and responses (Kanther et al., 2014). Equally, the immune system provides feedback in sculpting the microbial community structure (Kelly and Salinas, 2017; Tarnecki et al., 2019). If these finely balanced communities are disrupted, to a state known as dysbiosis, resulting health complications and disease may occur. The fish skin microbiome has been reported to change following stressful events, such as high stocking densities and hypoxia 
100 (Boutin et al., 2013), in fish showing clinical signs of gastrointestinal enteritis (Legrand et al., 101 2018), and also following viral infection (by salmonid alphavirus; see Reid et al., 2017),

102 bacterial infection (by Photobacterium damselae; see Rosado, Xavier, et al., 2019) and 103 macroparasitism (by the sea lice Lepeophtheirus salmonis; see Llewellyn et al., 2017). In all 104 of these cases, there was a decrease in abundance of reputedly beneficial taxa, concurrent with an increase of opportunistic pathogens. The resulting theory is that dysbiosis within the skin microbiome causes fish to become more susceptible to secondary bacterial infections. This has been shown for exposure to the antimicrobials rifampicin in Gambusia affinis Baird \& Girard (see Carlson et al., 2015) and potassium permanganate (Mohammed and Arias, 2015) in Ictalurus punctatus Rafinesque, where increased mortality occurred for dysbiotic fish 110 compared with controls when challenged with the disease-causing organisms Edwardsiella ictaluri and Flavobacterium columnare, respectively.

A limitation in the majority of microbiome studies, regardless of host species, is a focus on the bacterial community only with little or no attention given to the remaining microbial community members. This includes microeukaryotes, a taxonomic group that encompasses protists, microfungi, microalgae, and microbial metazoans (Bass and del Campo, 2020; del Campo et al., 2019), as well as viruses that infect an expansive host range including microeukaryotes, bacteria and the animal host (Gadoin et al., 2021). Microeukaryotic communities are well described in some settings, such as the contribution of microalgae to primary production in the ocean (Benoiston et al., 2017). The relationships between microeukaryotes and animal hosts have predominantly focussed on parasitism and pathogenesis, yet microeukaryotes play an intricate role in the broader microbial community of host-associated niches. One of the best-described examples is Blastocystis, a protist commonly found to colonise the gut of humans and other animal hosts. Its presence is thought to correlate with protection against several gastrointestinal inflammatory diseases by interacting with the bacterial community to promote a healthy microbiome (Laforest-Lapointe and Arrieta, 2018), specifically via an associated increase of bacterial diversity and strong cooccurrence patterns with reputed beneficial bacteria (Audebert et al., 2016; Beghini et al., 2017). The full role Blastocystis plays in human health remains unresolved and controversial. The extent of interactions occurring between bacteria and microeukaryotes and/or viruses in the fish skin microbiome is largely unknown and unreported.

Tilapia are the most widely farmed finfish in global aquaculture, produced in over 170 countries. Numerous species of tilapia are farmed, dominated by Nile tilapia (Oreochromis niloticus L.), and predominantly in lower-middle income countries (LMICs) across the SouthEast Asian, African and South American continents (FAO, 2020b). Given their fast growth, adaptability to a variety of environmental culture conditions, and resilience against both disease and poor water quality, tilapia are now a production staple for many LMICs, and colloquially is often referred to as the aquatic chicken (FAO, 2020a). Whilst some aquaculture species grown in LMICs, such as shrimp, are high-value products for export, the bulk of tilapia production is for domestic markets. As a consequence, fewer regulations exist for tilapia production (El-Sayed, 2019) and there has been far less scientific research for optimising sustainable production compared to some other high-value teleost species, such as Atlantic salmon.

Aquaculture in Malawi is in its relative infancy compared with other countries in Africa and Asia; nevertheless, production has seen on average a 24\% yearly growth between 2006 and 2016 (CASA, 2020). The levels of intensification or disease incidence seen in Malawi are low compared with Asia, but as demand increases, disease levels will inevitably increase also. Tilapia species cultured in Malawi include Coptodon rendalli Boulenger and Oreochromis shiranus Boulenger, with the notable absence of Nile tilapia, which is considered an invasive species. To fully elucidate the influence of microbiomes on fish health during disease 
processes, we need to better understand the relationships between the microbial diversity, community variance and structure in the mucosal surfaces of fish and those in the aquatic environment, including microeukaryotes (often excluded from microbiome studies), for disease-free populations. In this study therefore, we applied high throughput DNA sequencing for metabarcoding of the $16 \mathrm{~S}$ and $18 \mathrm{~S}$ ribosomal RNA (rRNA) small subunit (SSU) marker genes (which are conserved within prokaryotes and eukaryotes, respectively), to characterise the microbial communities of pond water and tilapia skin (C. rendalli and $O$. shiranus) from earthen aquaculture ponds in Malawi. With these data, we investigated the relationships between the pond water and skin microbiome. We identified differentially enriched and core taxa within the tilapia skin microbiome that are likely to play an important biological role for the host and may provide notable taxa for future studies to interpret disease events.

\section{Materials and methods}

\subsection{Sample collection}

164 Seven tilapia aquaculture earthen ponds were sampled in October 2017 from two pond systems in Malawi. Two ponds from a commercial farm were located in Maldeco, and a further five ponds from a community pond syndicate were $200 \mathrm{~km}$ further south in Blantyre

167 (Supplementary Fig. 1). Two samples types were collected: pond water and tilapia skin swabs

168 (Table 1). Pond surface water was collected from five locations within each pond by passing $169200 \mathrm{~mL}$ of water through a polycarbonate filter $(0.4 \mu \mathrm{m}$ pore, $47 \mathrm{~mm}$ diameter, Whatman $)$. The 170 volumes of water filtered were affected by the amount of organic/particulate matter in the samples such that volumes were sampled until filters became saturated and prevented further filtration. Mucosal skin samples of tilapia (mix of $C$. rendalli and $O$. shiranus) were collected by swabbing the entire length of the lateral flanks (along the lateral line) of the fish three times (Delamare-Deboutteville et al., 2021). Filters were preserved in 100\% molecular grade ethanol, while swabs were preserved in RNAlater (Qiagen), and stored at ambient temperature until transferred to the UK for prolonged storage at $-20{ }^{\circ} \mathrm{C}$, until used for DNA extraction and sequencing.

Table 1. Details of pond sites and samples for the pond water and fish skin swabs obtained from Malawian tilapia aquaculture ponds.

\begin{tabular}{|c|c|c|c|c|c|}
\hline $\begin{array}{l}\text { Pond } \\
\text { system } \\
\text { location }\end{array}$ & $\begin{array}{l}\text { Pond } \\
\text { site }\end{array}$ & $\begin{array}{l}\text { No. pond } \\
\text { water } \\
\text { samples }\end{array}$ & $\begin{array}{l}\text { No. fish } \\
\text { skin } \\
\text { swabs * }\end{array}$ & Cultured species & $\begin{array}{l}\text { Mean fish } \\
\text { length (mm) } \\
\pm \text { Std Dev }\end{array}$ \\
\hline $\begin{array}{l}\text { Blantyre, } \\
\text { Malawi }\end{array}$ & 1 & 5 & 2 & Coptodon rendalli & $115 \pm 10.6$ \\
\hline $\begin{array}{l}\text { Blantyre, } \\
\text { Malawi }\end{array}$ & 2 & 5 & 1 & Coptodon rendalli & $125 \pm 17.1$ \\
\hline $\begin{array}{l}\text { Blantyre, } \\
\text { Malawi }\end{array}$ & 3 & 5 & $7(5)$ & $\begin{array}{l}\text { Coptodon rendalli, } \\
\text { Clarias gariepinus }\end{array}$ & $\begin{array}{l}149 \pm 8.7 \\
\text { N/A }\end{array}$ \\
\hline $\begin{array}{l}\text { Blantyre, } \\
\text { Malawi }\end{array}$ & 4 & 5 & 8 & $\begin{array}{l}\text { Coptodon rendalli, } \\
\text { Oreochromis shiranus }\end{array}$ & $\begin{array}{l}137 \pm 3.8 \\
122 \pm 5.4\end{array}$ \\
\hline $\begin{array}{l}\text { Blantyre, } \\
\text { Malawi }\end{array}$ & 5 & 5 & 5 & Coptodon rendalli & $162 \pm 16.1$ \\
\hline
\end{tabular}




\begin{tabular}{lccccc}
$\begin{array}{l}\text { Maldeco, } \\
\text { Malawi }\end{array}$ & 6 & 5 & $6(4)$ & Oreochromis shiranus & $222 \pm 27.3$ \\
$\begin{array}{l}\text { Maldeco, } \\
\text { Malawi }\end{array}$ & 7 & 5 & $4(3)$ & Oreochromis shiranus & $212 \pm 11.3$ \\
\hline
\end{tabular}

181

182

183

$\begin{array}{llll}\text { Total } & 7 & 35 & 33(28)\end{array}$

*Numbers in brackets refer to the number of $18 \mathrm{~S}$ rRNA samples successfully sequenced, where this differs from 16S rRNA samples.

\subsection{DNA extraction}

Ethanol was removed from pond water filters by freeze-drying (ScanVac CoolSafe Pro, $4 \mathrm{~L}$ condenser at $-110^{\circ} \mathrm{C}$ ) and filters were then stored at $-80^{\circ} \mathrm{C}$. RNAlater was removed from fish swab samples by vortexing the swabs for 30 seconds in $23 \mathrm{~mL}$ of $1 \mathrm{x}$ phosphate buffered saline to allow detachment of microbes. The swab and solution were transferred to a syringe for filtration with a $0.22 \mu \mathrm{m}$ Sterivex (Millipore) filter unit. Following ethanol and RNAlater removal from filters and swabs, DNA was extracted with a CTAB/EDTA/chloroform method adapted from Bramwell et al. (1995) and Lever et al. (2015), and is available in full at (https://dx.doi.org/10.17504/protocols.io.bw8gphtw).

Briefly, for DNA extraction filters were first suspended in $570 \mu 1$ lysis buffer ( $30 \mathrm{mM}$ Tris, 30 mM EDTA, pH 8), freeze-thaw lysed in liquid nitrogen and homogenised by beadbeating with Lysing Matrix A Bulk Beads (Garnet) on the Qiagen TissueLyser II for 40 seconds at $30 \mathrm{~Hz}$. The sample suspension was digested with $1 \mu \mathrm{L}$ Ready-Lyse lysozyme $(1000 \mathrm{U} / \mu \mathrm{L}$, Epicentre), and $3 \mu \mathrm{L}$ proteinase K $(20 \mathrm{mg} / \mathrm{mL}$, Sigma) in $30 \mu \mathrm{L}$ SDS $(10 \% \mathrm{w} / \mathrm{v})$ for 1 hour at $55{ }^{\circ} \mathrm{C}$. Samples were then incubated for 10 minutes at $65{ }^{\circ} \mathrm{C}$ in $120 \mu \mathrm{L} \mathrm{NaCl}(5 \mathrm{mM})$ and CTAB solution (hexadecyltrimethylammonium bromide, $96 \mu \mathrm{L}, 10 \% \mathrm{w} / \mathrm{v}$ ). An equal ratio of sample and 24:1 chloroform:isoamyl alcohol (Acros Organics) were used for extractions, with centrifugation at $14,000 \mathrm{x} \mathrm{g}, 4^{\circ} \mathrm{C}$ for 5 minutes. The aqueous layer was retained for a second extraction, after which $1 \mu \mathrm{L}$ of linear polyacrylamide solution (GenElute LPA, Sigma) was added to aid precipitation with 0.7 volumes isopropanol. Following overnight incubation at 4 ${ }^{\circ} \mathrm{C}$, samples were centrifuged at $21,000 \mathrm{x} \mathrm{g}, 4^{\circ} \mathrm{C}$ for 30 minutes and the resulting pellet washed with $70 \%$ ethanol. After 10 minutes of centrifugation at $21,000 \mathrm{x} g$ and pipetting off the ethanol, DNA pellets were resuspended in TE buffer (10 mM Tris-HCl, $1 \mathrm{mM}$ EDTA, pH 8) and stored at $-20{ }^{\circ} \mathrm{C}$ until used for sequencing.

\subsection{Metabarcoding}

Metabarcoding of prokaryotic and microeukaryotic SSU rRNA marker genes was performed by PCR amplification with the Earth Microbiome Project recommended primers. The $16 \mathrm{~S}$ rRNA V4 hypervariable region was targeted by $515 \mathrm{~F}$ (Parada) 5'GTGYCAGCMGCCGCGGTAA-3' (Parada et al., 2016); 806R (Apprill) GGACTACNVGGGTWTCTAAT (Apprill et al., 2015), and the 18S rRNA V9 hypervariable region was targeted by 1391f 5'-GTACACACCGCCCGTC-3' (Lane, 1991) and EukBr 5'TGATCCTTCTGCAGGTTCACCTAC-3' (Medlin et al., 1988). Amplification conditions for $16 \mathrm{~S}$ V4 were $98{ }^{\circ} \mathrm{C}$ for 30 seconds; 30 cycles of $98{ }^{\circ} \mathrm{C}$ for 10 seconds, $55^{\circ} \mathrm{C}$ for 30 seconds, $72{ }^{\circ} \mathrm{C}$ for 30 seconds; and a final extension of $72{ }^{\circ} \mathrm{C}$ for 2 minutes. $18 \mathrm{~S}$ V9 conditions were the same, with the exception of an annealing temperature of $60{ }^{\circ} \mathrm{C}$. Samples were amplified and multiplexed in a 1-step PCR with a dual-indexing scheme (Kozich et al., 2013) prior to sequencing by the University of Exeter Sequencing Service on the Illumina MiSeq, using v2 chemistry ( $250 \mathrm{bp}$ paired-end for $16 \mathrm{~S}$ and $150 \mathrm{bp}$ paired-end for $18 \mathrm{~S}$ ). The sequencing runs included four positive controls (ZymoBIOMICS® Microbial Community DNA standard, lot 
number ZRC190811) and six negative controls comprising nuclease free water carried through the entire DNA extraction and PCR amplification.

\subsection{Bioinformatics processing}

All bioinformatics and statistical analyses were performed in R v3.6.3. Following sample demultiplexing, reads were quality controlled and processed by the DADA2 pipeline v1.14 (Callahan et al., 2016). Briefly, quality profiles of paired reads were inspected and forward and reverse reads were truncated at $200 \mathrm{bp}$ and $160 \mathrm{bp}$, respectively for prokaryotes, and $100 \mathrm{bp}$ for both reads of microeukaryotes. Amplicon sequence variants (ASVs) were then inferred with DADA2's pooling method to enhance the detection of rare ASVs. Paired reads were merged if they achieved a minimum overlap of $100 \mathrm{bp}$ for prokaryotes and $25 \mathrm{bp}$ for microeukaryotes. To remove off-target sequencing artefacts, final ASVs were only retained for the lengths 250 $-256 \mathrm{bp}$ for prokaryotes and $90-150 \mathrm{bp}$ for microeukaryotes. Chimeras were removed and taxonomy assigned to each ASV against the SILVA SSU v138 taxonomic database (Quast et al., 2012). For the microeukaryotic dataset, only ASVs classified by SILVA as eukaryotic were retained and final taxonomic classifications of these ASVs were made by the PR2 v4.12 taxonomic database (Guillou et al., 2012). Accuracy of the taxonomic assignment was assessed in positive controls, with all members of the ZYMO mock community present, as expected (Supplementary Fig. 2).

A phylogenetic tree of ASVs was constructed with Phangorn v2.5.5 (Schliep, 2010) by first generating a neighbour-joining tree, followed by fitting a generalised time reversible substitution model to generate a maximum likelihood tree. The statistical tool Decontam v1.6 (Davis et al., 2018) was used to identify contaminating ASVs by looking at the prevalence in negative controls, with standard parameters baring a 0.5 prevalence threshold. Thus, all sequences found at greater prevalence in negative controls than positive samples were classed as contaminants and were removed from the ASV table.

ASVs and sample data were parsed to Phyloseq v1.30 (McMurdie and Holmes, 2013) for all subsequent quality control and data analyses. To remove sequencing noise, only ASVs that reached a $2 \%$ prevalence threshold across samples were retained. Furthermore, any ASVs taxonomically assigned as chloroplasts, mitochondria, eukaryotic or unclassified at kingdom level were removed from the prokaryotic dataset. Additionally for the microeukaryotic dataset, 14 sequences classified as Craniata were removed, as these most likely represented fish sequences. As a result, the characterisation of fish skin microeukaryotes was limited due to the high levels of contaminating host $18 \mathrm{~S}$ rRNA sequences $(98.6 \%)$ in swab samples.

\subsection{Statistical and data analysis}

Alpha diversity metrics were calculated with Phyloseq on counts rarefied to the minimum sequencing depth. The difference between pond sites was statistically tested by Welch's ANOVA and post-hoc pair-wise Games-Howell test, following confirmation of normality. Further testing between sample types utilised lmerTest v3.1-3 (Kuznetsova et al., 2017) to perform a linear mixed-effects model that accounted for pond site as a random effect. A Pearson's correlation coefficient was used to test for correlation of Chaol richness and Shannon diversity between sample types.

Beta diversity analysis was performed with compositional data analysis principles. These comprise log-based transformations, which cannot be performed on zero values. Therefore, ASV counts were subjected to a count zero multiplicative replacement method in zCompositions v1.3.4 (Palarea-Albaladejo and Martín-Fernández, 2015). A centred log-ratio (CLR) transformation was then applied to ASV counts with the CoDaSeq package v0.99.6 (https://github.com/ggloor/CoDaSeq). Euclidean distance was calculated on log-ratios and ordinated by PCoA biplot with FactoExtra v1.0.7 (https://github.com/kassambara/factoextra). 
Statistical differences between pond site and sample type groups were conducted on the Euclidean distance matrix by permutational multivariate analysis of variance (PERMANOVA) and permutation tests for homogeneity of multivariate dispersions, implemented in Vegan v2.5-6 (Dixon, 2003).

Community composition was presented as heat trees of taxon relative abundance with Metacoder v0.3.4 (Foster et al., 2017), utilising a Davidson-Harel layout algorithm. Differential abundance between sample types was assessed by CornCob v0.1 (Martin et al., 2020), utilising the Wald Chi-Squared test and accounting for pond site as a random effect. Core microbiome analysis was performed on ASVs amalgamated to genus level and rarefied to the minimum sequencing depth. Classification of the fish skin core genera was performed with the Microbiome package v2.1 (Lahti and Shetty, 2017) based on a prevalence threshold of $80 \%$ and a detection threshold of $0.01 \%$ in all swab samples. Heatmaps of core genera and discriminant taxa were depicted as heatmaps of CLR abundance of non-rarefied counts by pheatmap v1.0.12 (https://github.com/raivokolde/pheatmap).

The significance level and false discovery rate of 0.05 was set for all statistical analyses.

\subsection{Data availability}

291 Raw sequencing reads were deposited in the European Nucleotide Archive under the accession PRJEB46984. Data processing, analysis scripts and final ASV tables are accessible at https://github.com/jamiemcm/Malawi_Tilapia_Microbiomes.

\section{Results}

Following quality control and filtering, the final prokaryotic dataset contained 969,562 reads and 5782 ASVs from all skin swab and pond water filter samples, respectively, collected in this study (67 samples). The eukaryotic dataset comprised 94,611 reads, 1659 ASVs from the 62 samples collected. Full read counts per library, including break down between skin swabs and pond water filters, are available in Supplementary Table 1.

\subsection{Phytoplankton communities}

303 Compositional approaches (CLR) to beta diversity were applied to explore variation in microbial community composition and abundance of pond water between sites are shown in Figures 1A and 1B. Clear clustering of water samples by pond site was evident, with the position of mean group centroids corresponding to site shown to be significantly different from each other according to PERMANOVA for both prokaryotic $\left(\mathrm{F}(6,28)=34.29, R^{2}=0.88, p<\right.$ $0.001)$ and microeukaryotic $\left(\mathrm{F}(6,28)=15.12, R^{2}=0.76 p<0.001\right)$ communities. Dispersion of the pond water samples collected within each site was relatively small, particularly with respect to prokaryotes (Fig. 1B). However, largely due to pond site 2, dispersion in prokaryotes differed significantly according to permutation tests for homogeneity of multivariate dispersions (Prokaryotes $\mathrm{F}(6,28)=3.95, p=0.003$; Eukaryotes $\mathrm{F}(6,28)=0.87, p=0.53$ ).

While pond location had a strong influence on the separation of pond water samples, the clustering observed in prokaryotes of the tilapia skin was less distinctive (Fig. 1C). There was a significant difference between the mean centroid position of each pond site by PERMANOVA $\left.\mathrm{F}(6,25)=4.19, R^{2}=0.50, p<0.001\right)$ and significant dispersion between fish within the same pond $(\mathrm{F}(6,25)=5.32, p=0.009)$.

Specific taxa were associated with driving community separation between pond sites. Figure 1 shows the top 15 contributing taxa plotted as arrows on each biplot, with their CLR abundance depicted in the accompanying heatmaps. In pond water, microeukaryotes included several diatoms (ASV6: Cyclotella and ASV16: Aulacoseira), the presence of which separated pond site clusters 2,3 and 6,7 from 1,4,5. ASV47: Eukaryota was the major taxon - found at 
high abundance - discriminating pond site cluster 1,4,5 from the remaining ponds, and a BLASTn search of this ASV revealed 90\% similarity to the microalgae Cryptomonas. In the pond water prokaryotic community, photosynthetic Cyanobacteria were particularly prevalent in pond site clusters 2,3 and 6,7, with apparently differing Cyanobium ASVs (ASV3, ASV4) in each cluster, and a shared Synechocystis (ASV1). Pond site cluster 1,4,5 was distinguished by typical freshwater planktonic Proteobacteria (ASV9: Polynucleobacter, ASV111: Limnohabitans and ASV22: Comamonadaceae), among others. For fish skin prokaryotes, three out of the top 15 discriminant taxa (ASV43: Aquabacterium, and ASV16, ASV74: Comamonadaceae) explained the separation of pond cluster 1,4,5 only. Many of these identified taxa shared taxonomic affiliation to the aforementioned prokaryotes of pond water, but were represented by separate ASVs than those previously identified, such as ASV17, ASV24: Cyanobium, ASV16, ASV74: Comamonadaceae and ASV6, ASV73, ASV135: Actinobacteria hgcl clade (Warnecke et al., 2004).

Alpha diversity metrics gave an insight into species diversity of the pond water samples from different pond sites as determined through assessing community richness (Chao1) and evenness (Shannon diversity and Inverse Simpson diversity) (Fig. S3A,B). Applying Welch's ANOVA showed a significant difference between both prokaryotic and microeukaryotic communities of each pond site for all diversity metrics (Tab. S2). No correlation was found between prokaryotic and microeukaryotic communities for the mean richness/diversity metric of each pond site (Fig. S3D) (Pearson's correlation: Chao1 richness $R=0.56, p=0.19$; Shannon diversity $R=0.35, p=0.44$; InvSimpson $R=-0.024, p=0.96$ ).

\subsection{Microbial niche separation}

We used measures of alpha and beta diversity to explore the influence of the environment (pond water) in shaping tilapia skin prokaryotic microbiota. When controlling for pond site as a random effect in linear mixed-effects modelling, ASV richness of the fish skin was found to be significantly lower than pond water (by $503 \pm 59.49 \mathrm{ASVs}, R^{2} \mathrm{c}=0.61, p<0.001$ ) (Fig. 2A). Shannon diversity of fish skin and pond water varied according to pond site, however, there was no overall clear separation between the sample types when the aforementioned statistical model was applied (pond water $4.96 \pm 0.12$, fish skin $4.72 \pm 0.15, R^{2} \mathrm{c}=0.11, p=0.115$ ) (Fig. 2B). Additionally, neither richness nor diversity were correlated between the fish skin and pond water when comparing between pond sites, according to Pearson correlation tests (Chao1 richness $R=0.18, p=0.71$; Shannon diversity $R=0.11, p=0.81$ ) (Fig. 2C,D). Pair-wise comparisons were made of the beta diversity (Aitchison distance) between samples within each pond site (Fig. 2E) and this showed pond water samples clustered closely together, but greater dispersion was apparent between fish skin samples. The largest Aitchison distance values were seen in the comparisons between pond water and fish skin samples, indicating different prokaryotic community structures between these niches. Although these structures were made up of shared taxa, albeit at different abundances, with 4020 of a total 5782 ASVs detected in both pond water and fish skin (Fig. 2F).

Depicting taxonomic composition of prokaryotic and microeukaryotic communities from skin swab and pond water samples as phylogenetic heat trees (see Fig. S4) illustrates much of the diversity for individual samples is accounted for by rare taxa found at low abundance. The prokaryotic community composition at coarse taxonomic levels was overall very similar between the pond water and skin environments, although divergence emerges at finer taxonomic resolution. For the microeukaryotic community, a far greater overall taxonomic diversity was observed in pond water than on skin, with numerous rare taxa. However, skin diversity was artificially under-sampled due to the over-amplification of tilapia host 18S RNA gene copies. 
Taxonomic relative abundance (depicted as dot plots of prokaryotes at class level and microeukaryotes at division level) highlights the differences between pond water and fish skin niches (Fig. 3). According to differential abundance statistical testing, the bacterial classes Gammaproteobacteria and Clostridia were enriched (FDR <0.05) in the fish skin. Pond water by contrast had enriched abundances of Cyanobacteria, Actinobacteria, Bacteroidia, Verrucomicrobiae, Planctomycetes, Kapabacteria and Chloroflexia. Differential abundance testing controlled for pond site as a random effect, however, the degree and consistency of enrichment did vary between pond sites.

Within these high level taxa, individual prokaryotic taxa were (FDR <0.05) differentially abundant between pond water and the skin (Fig. 4). In general, these taxa followed phylogenetic trends of enrichment, whereby if a taxon was found to be differentially abundant, all other identified taxa within the same phylum were enriched in the same sample type. The pond water was differentially enriched with several taxa associated with key nutrient cycling processes in the aquatic environment, such as the photoautotrophs Cyanobium, Synechocystis and Microcystis, and the methanotroph Methylocystis. Meanwhile, selected ASVs found to be differentially enriched at the skin surface included taxa previously reported as fish microbiome commensals, such as Cetobacterium, as well as additional fish related taxa, which in some cases can be associated with diseases, such as Aeromonas, Pseudomonas, Staphylococcus, and Streptococcus.

\subsection{Tilapia species differences}

This study featured two tilapia species commonly cultured in Malawi (Coptodon rendalli and Oreochromis shiranus). No significant difference of prokaryotic community alpha diversity were observed between species (Fig. S5) and while beta diversity did showed potentially unique community structures between species, this only explained $11 \%$ of variance. Pond site in contrast explained $50 \%$ of variance in beta diversity. Additionally, intra-species dispersion of $C$. rendalli prokaryotic communities (Average distance to median 54.49) was similar to any inter-species dispersion observed between $C$. rendalli and $O$. shiranus at Blantyre (Average distance to median 53.79).

\subsection{Tilapia skin core microbiome}

To further explore specific taxa prevalent within the skin microbial communities we identified 14 prokaryotic core genera of tilapia skin. Abundances of these core genera are depicted for both fish skin and pond water samples in Figure 5. Two of the prokaryotic core genera had a clear enrichment of abundance in the fish skin versus to pond water, namely ASV47: Pseudomonas and ASV8731: Sphingomonas. The remaining prokaryotic genera were found at high abundance in both pond water and skin samples, despite being classified as part of the tilapia skin core microbiome.

\section{Discussion}

Previous work has highlighted the collective contributions of microbial symbionts, the host and the environment to fish health and disease susceptibility under the pathobiome concept (Bass et al., 2019). Applying this framework to aquaculture production of finfish, the skin mucosal surface microbiome and its direct interface with the environment is likely to play a role in the maintenance of fish health and disease resilience. However, relationships between the microbial assemblages on the skin of fish in culture and their aquatic environment remain poorly established. Here, we characterised the prokaryotic and microeukaryotic communities of the tilapia skin mucosal surface and accompanying pond water environment in aquaculture ponds of southern Malawi in the absence of detectable disease to develop a holistic 
understanding of the relationships between these microbial communities and niches in healthy animals and environments, and against which future studies may assess how microbial dysbiosis contributes to disease onset.

In this study, biogeographic factors played a key role in determining the diversity and structure of pond water microbial communities. Pond location explained $88 \%$ of prokaryotic and $76 \%$ of microeukaryotic beta diversity separation in microbial abundance profiles. Significant differences in richness and alpha diversity were observed between the seven pond sites. In freshwater ecosystems, both neutral and deterministic processes contribute to the separation of microbial assemblages (Lear et al., 2014; Lee et al., 2013). Interestingly, just over $1 \%$ of prokaryotic pond water ASVs were detected in all seven pond sites, suggesting limited species dispersal and/or distinct micro-ecologies between ponds. Numerous environmental selective pressures could play a role in the divergence in ASVs between ponds, such as alternative feeding regimes (Deng et al., 2019), differences in water physiochemistry (Qin et al., 2016) and differences in pond treatments, that can include the use of probiotics (Wu et al., 2016) and manure fertilisers (Minich et al., 2018). Within a pond complex, some of these factors will be conserved, such as weather and water source. Yet microbial community divergence was still observed between ponds in the Blantyre pond complex, with two notable clusters of pond sites (1,4,5 and 2,3).

The tight clustering of pond water samples was concurrent between both prokaryotic and microeukaryotic communities suggesting cross-domain relationships shaped by ecological or environmental processes. This connection has recently been observed in shrimp culture ecosystems, with the deterministic process of homogenous selection largely responsible (Zhou et al., 2021). In this theory, each pond site cluster represents a comparable set of environmental conditions (be it nitrogen, phosphorous or oxygen availability) that exerts strong selective pressures on both prokaryotic and microeukaryotic communities (Zhou and Ning, 2017). Additionally, direct cross-domain ecological interactions may contribute to the observed trends. For instance, phagotrophic protists and their prokaryotic prey have negative interactions (Sherr and Sherr, 2002), while microalgae and bacteria can show all manner of symbiotic relationships, including extensive cross-feeding (Fuentes et al., 2016; Ramanan et al., 2016).

The close proximities of microbial communities of pond water with those in the fish outer mucosal surfaces mean they are physically closely interconnected, yet pond and skin microbiomes clearly differ. Our results demonstrate these differences in prokaryotic community structure, with ASV richness differing significantly, and separation by beta diversity. However, there was no significant difference in alpha diversity, a finding previously reported in freshwater and marine environments (Chiarello et al., 2015; Reinhart et al., 2019; Webster et al., 2018). At finer taxonomic scales further separation between the skin and pond water profiles was seen, and conserved across all ponds sites, with 25 ASVs differentially enriched at the fish skin mucosal surface. The abundances assessed at coarse taxonomic classifications reflected previous reports, namely that Proteobacteia (and in particular Gammaproteobacteria) dominated the fish skin mucosal surface, as seen in a variety of freshwater cichlids (Krotman et al., 2020); reviewed in depth by Gomez and Primm (2021). The next most abundant bacterial classes in the fish skin were Verrucomicrobiae, Bacteroidia and Clostridia. The pond water was similarly dominated by Proteobacteria, followed by Cyanobacteria and Planctomycetes, which is in accordance with a previous report of the bacterioplankton community in Nile Tilapia aquaculture ponds in China (Fan et al., 2016).

Despite divergent abundance profiles, there was a high number of taxa shared between pond water and skin mucosa. Only, $8 \%$ of the total fish skin ASVs were unique to the skin, which contrasts with that for reports on some other fish species. For example, in freshwater river-dwelling mature northern pike, Esox lucius L., 36\% of skin taxa were not detected in samples of the surrounding water (Reinhart et al., 2019). In a study on freshwater Atlantic 
salmon, Salmo salar L., this figure was 73\% (Webster et al., 2018), where fry (8-9 months post-hatch) were sampled from both wild rivers and hatcheries. Both of these studies were in natural aquatic environments and flow-through systems with high water exchange rates which is very different to typical carp and tilapia earthen aquaculture ponds, where daily water exchange rates tend to be very limited, typically a maximum of $20 \%$ total pond volume (Nhan et al., 2008). In fact, often in Africa and Asia during dry seasons, due to lack of water availability, there is no daily water exchange at all in tilapia earthen aquaculture ponds. Such static conditions and high stocking densities may be reflected in a greater microbial crossover between fish skin and pond water. Given the common taxa seen between the tilapia skin and pond water environments, it is noteworthy that we found no correlation in ASV richness or Shannon diversity between the pond and skin niches within each pond site. This supports the hypothesis that the skin and pond water niches support uniquely structured microbial communities.

The core microbiome refers to taxa found in the majority of samples which, by inference, may therefore play an important functional role in the microbiome. Fourteen prokaryotic core genera (from a total 770 genera) were identified in tilapia skin, consistent with previously published findings from other studies of fewer than 20 core OTUs on fish skin (reviewed by Gomex and Primm 2021; Rosado, Pérez-Losada, et al., 2019). Among the core genera found in the tilapia skin, Cetobacterium has been widely reported as a core genus in the gut of freshwater fish (Liu et al., 2016; Sharpton et al., 2021), including tilapia (Bereded et al., 2020; Elsaied et al., 2019). This may represent an important functional symbiont, and is reputed to synthesise vitamin B12 and antimicrobial metabolites (Tsuchiya et al., 2007). Other core genera and differentially enriched taxa of the skin are listed in Supplementary Table 3. Ten of the fish skin core genera were also detected at relatively high abundance in pond water. These include Cyanobium and Methylocystis (two of the most abundant and differentially enriched phytoplankton in pond water), which may have resulted from swab sampling incorporating some residual pond water. Some studies propose only retaining ASVs unique to swab samples and those statistically enriched from water samples to avoid this possible complication (Krotman et al., 2020). This approach, however, risks underestimating diversity and missing key taxa of the fish skin that through mucosal sloughing may still be detected at high abundances in water. The majority of studies make no corrections; instead acknowledging crossover is inevitable and representative of these niches.

Whilst the current study included two different species of tilapia, geographic location (and the associated environmental factors) of each pond site appeared to be a stronger influence of prokaryotic fish skin communties than any species differences observed between $C$. rendalli and $O$. shiranus. This suggests species is a complicating factor in our study but is of lesser importance when considering the broader trends of microbial community separation between pond water and fish skin. The importance of habitat over host taxonomy has previously been demonstrated for a large scale study of marine fish gut microbiomes (Kim et al., 2021).

Several of the bacterial genera we found to be differentially abundant in fish skin contained species pathogenic to tilapia, including Aeromonas (hydrophila) (see Dong et al., 2017), Streptococcus (agalactiae) (see Zhang, 2021) and Pseudomonas (fluorescens) (see Hal and El-Barbary, 2020). In addition to these fish skin enriched genera, further potentially pathogenic taxa were detected in pond water and fish skin. Namely, Plesiomonas (shigelloides) (see Liu et al., 2015), Flavobacterium (columnare) (see Dong et al., 2015) and Acinetobacter spp. an emerging group of freshwater fish pathogens (Malick et al., 2020). Likewise, among the detected microeukaryotic genera, there were species pathogenic to tilapia, including the parasitic ciliate Ichthyophthirius multifiliis (see El-Dien and Abdel-Gaber, 2009) and two skintargeting pathogenic oomycetes, Aphanomyces invadans (OIE, 2013) and Saprolegnia parasitica (see Ellison et al., 2018). The metabarcoding of short hypervariable regions of 
marker genes does not allow us to accurately assign species or strain level classifications to determine their pathogenicity, and the detected genera also contain numerous non-pathogenic species. These 'pathogens' were all at very low (typically less than 1\%) relative abundances, and indeed none of these ponds had reported incidence of disease. This work does not preclude the fact that other pathogens may be present below the limits of detection thresholds or taxonomic resolution. Presence may raise the risk of opportunistic disease as primary or secondary pathogens if environmental stressors create a state of dysbiosis to favour their propagation, leading to disease onset (Bass et al., 2019).

Fish skin microbiomes are inherently variable between populations (Webster et al., 2018), species (Chiarello et al., 2018), individuals in the same environment, and even across different areas of skin (anal, caudal, dorsal and pectoral fins) of the same individual (Chiarello et al., 2015). We observed separation of fish skin communities according to environment (pond site), however inter-individual dispersion within pond sites was considerable, and the degree of dispersion between pond sites was significantly different. Host genetics is thought to contribute to the inter-individual variation of fish skin communities (Boutin et al., 2014). Additionally, fish age has been seen to influence individual taxa abundances but offers a limited explanation of inter-individual variation at the microbial community level (Rosado et al., 2021). Furthermore, the time of day of sampling has a large influence on fish skin microbiota (Ellison et al., 2021). Longitudinal studies that monitor the microbiomes of individual tilapia in aquaculture ponds over time would provide valuable insight into their dynamics and help inform on the variability on responses to the physicochemical fluctuations in these environments. However, repetitive sampling of individual fish and the stress imposed, including netting, may disrupt mucosal surfaces and risks inducing microbial dysbiosis (Minniti et al., 2017).

In contrast to the variability of fish skin, pond water communities were more consistent across sample sites. At most pond sites, one photoautotroph (Cyanobium or Synechocystis) was dominant, at up to $20 \%$ relative abundance. While Synechocystis is well studied as a model organism, little is known of Cyanobium and its large contribution to primary production despite being among the most abundant taxa in carp aquaculture ponds (Marmen et al., 2021) and freshwater lakes (Rogers et al., 2021). Additionally, the harmful algal bloom agent Microcystis was detected at very high abundance in pond sites 5, 6 and 7, which is concurrent with observations of rich blue-green algae during sampling. Microcystis (see Marmen et al., 2021, 2016; Zimba and Grimm, 2003), and its toxin microcystin, are frequently detected in aquaculture ponds and can have toxic effects in tilapia (Abdel-Latif and Khashaba, 2017). Conversely, eukaryotic microalgae, in particular diatoms, contribute positively to the freshwater ecosystem as key primary producers and stabilisers of water quality (Guedes and Malcata, 2012; Li et al., 2017). The barbed spines of some diatoms (Chaetoceros spp.), however, can cause gill haemorrhage in saltwater aquaculture (Yang and Albright, 1992). Pond sites 2, 3 and 6 were dominated by several diatoms, including Cyclotella, Nitzschia and Aulacoseira. In other pond sites, many high abundance ASVs remained unclassified beyond kingdom level, however, BLASTn searches suggested several of these were photosynthetic microalgae and likely contribute to oxygen cycling.

\section{Conclusions}

This study highlights the diversity, structure and variance of the microbial communities found in tilapia skin and pond water, and characterises the microbiomes for 'healthy' earthen aquaculture ponds in Malawi. Future studies seeking to establish relationships between dysbiosis and disease states need to take into account the inter-individual variation between fish, and community variance across pond sites that also occurs within the same pond complexes. We found a large degree of taxa crossover between fish skin and pond water, some 
of which may be reflective of swab sampling bias, but also unique microbial communities supported by each niche. The identified core genera and differentially enriched taxa may represent conserved markers of the tilapia skin, whose presence and abundance should be considered in future dysbiosis events, albeit in most cases the functional role of these taxa at the fish skin remains to be determined. Developing a deeper understanding on the microbial communities, particularly those that interface between the aquatic environment and culture species from different geographies, is critical for understanding health risks in aquaculture species as production expands and intensifies, bringing with it an increased risk of dysbiosis and incidence of disease.

\section{Author contribution statement} Visualisation JM, DLC; Writing JM \& CRT; Editing JM, SA, DLC, DB, CC, JDD, CVM, JC, BT \& CRT.

\section{Funding}

This work was funded by the BBSRC/Newton Fund project (BB/N00504X/1). JM was supported by the BBSRC/South West Biosciences Doctoral Training Partnership (BB/M009122/1) with CASE partners WorldFish and Cefas. Sequencing was performed at the Exeter Sequencing Service, using equipment funded by the Wellcome Trust Institutional Strategic Support Fund (WT097835MF), Wellcome Trust Multi-User Equipment Award (WT101650MA) and BBSRC LOLA award (BB/K003240/1). This work was further supported by the CGIAR Research Program on Fish Agri-Food Systems (FISH) led by WorldFish. CC and JN salary was supported by WorldFish.

\section{Acknowledgements}

We thank, for their contributions to this work, Karen Moore, Audrey Farbos and Paul O'Neill from the Exeter Sequencing Service; Nicola Rogers for project management (Newton Fund project); and John Dowdle for lab management during the practical work.

\section{References}

603

Abdel-Latif, H.M.R., Khashaba, A.M.A., 2017. Subchronic toxicity of Nile tilapia with different exposure routes to Microcystis aeruginosa: Histopathology, liver functions, and oxidative stress biomarkers. Vet. World 10, 955-963. https://doi.org/10.14202/vetworld.2017.955-963

Abdel-Tawwab, M., Hagras, A.E., Elbaghdady, H.A.M., Monier, M.N., 2014. Dissolved Oxygen Level and Stocking Density Effects on Growth, Feed Utilization, Physiology, and Innate Immunity of Nile Tilapia, Oreochromis niloticus. J. Appl. Aquac. 26, 340355. https://doi.org/10.1080/10454438.2014.959830

Apprill, A., McNally, S., Parsons, R., Weber, L., 2015. Minor revision to V4 region SSU rRNA 806R gene primer greatly increases detection of SAR11 bacterioplankton. Aquat. Microb. Ecol. 75, 129-137. https://doi.org/10.3354/ame01753

Audebert, C., Even, G., Cian, A., Loywick, A., Merlin, S., Viscogliosi, E., Chabé, M., 2016. Colonization with the enteric protozoa Blastocystis is associated with increased diversity of human gut bacterial microbiota. Sci. Rep. 6, 25255. https://doi.org/10.1038/srep25255 Bass, D., del Campo, J., 2020. Microeukaryotes in animal and plant microbiomes: Ecologies of disease? Eur. J. Protistol. 76, 125719. https://doi.org/10.1016/j.ejop.2020.125719 Bass, D., Stentiford, G.D., Wang, H.-C., Koskella, B., Tyler, C.R., 2019. The Pathobiome in 
Animal and Plant Diseases. Trends Ecol. Evol. 34, 996-1008. https://doi.org/10.1016/j.tree.2019.07.012

Beghini, F., Pasolli, E., Truong, T.D., Putignani, L., Cacciò, S.M., Segata, N., 2017. Largescale comparative metagenomics of Blastocystis, a common member of the human gut microbiome. ISME J. 11, 2848-2863. https://doi.org/10.1038/ismej.2017.139

Benoiston, A.-S., Ibarbalz, F.M., Bittner, L., Guidi, L., Jahn, O., Dutkiewicz, S., Bowler, C., 2017. The evolution of diatoms and their biogeochemical functions. Philos. Trans. R. Soc. B Biol. Sci. 372, 20160397. https://doi.org/10.1098/rstb.2016.0397

Bereded, N.K., Curto, M., Domig, K.J., Abebe, G.B., Fanta, S.W., Waidbacher, H., Meimberg, H., 2020. Metabarcoding Analyses of Gut Microbiota of Nile Tilapia (Oreochromis niloticus) from Lake Awassa and Lake Chamo, Ethiopia. Microorganisms 8, 1040. https://doi.org/10.3390/microorganisms8071040

Bondad-Reantaso, M.G., Subasinghe, R.P., Arthur, J.R., Ogawa, K., Chinabut, S., Adlard, R., Tan, Z., Shariff, M., 2005. Disease and health management in Asian aquaculture. Vet. Parasitol. 132, 249-272. https://doi.org/10.1016/j.vetpar.2005.07.005

Boutin, S., Bernatchez, L., Audet, C., Derôme, N., 2013. Network analysis highlights complex interactions between pathogen, host and commensal microbiota. PLoS One 8, 1-16. https://doi.org/10.1371/journal.pone.0084772

Boutin, S., Sauvage, C., Bernatchez, L., Audet, C., Derome, N., 2014. Inter Individual Variations of the Fish Skin Microbiota: Host Genetics Basis of Mutualism? PLoS One 9, e102649. https://doi.org/10.1371/journal.pone.0102649

Bramwell, P.A., Barallon, R. V., Rogers, H.J., Bailey, M.J., 1995. Extraction and PCR amplification of DNA from the rhizoplane, in: Molecular Microbial Ecology Manual. Springer Netherlands, Dordrecht, pp. 89-108. https://doi.org/10.1007/978-94-011-03510_9

Callahan, B.J., McMurdie, P.J., Rosen, M.J., Han, A.W., Johnson, A.J.A., Holmes, S.P., 2016. DADA2: High-resolution sample inference from Illumina amplicon data. Nat. Methods 13, 581.

Carlson, J.M., Hyde, E.R., Petrosino, J.F., Manage, A.B.W., Primm, T.P., 2015. The host effects of Gambusia affinis with an antibiotic-disrupted microbiome. Comp. Biochem. Physiol. Part C Toxicol. Pharmacol. 178, 163-168. https://doi.org/10.1016/j.cbpc.2015.10.004

CASA, 2020. Aquaculture Sector Strategy - Malawi.

Chiarello, M., Auguet, J.-C., Bettarel, Y., Bouvier, C., Claverie, T., Graham, N.A.J., Rieuvilleneuve, F., Sucré, E., Bouvier, T., Villéger, S., 2018. Skin microbiome of coral reef fish is highly variable and driven by host phylogeny and diet. Microbiome 6, 147. https://doi.org/10.1186/s40168-018-0530-4

Chiarello, M., Villéger, S., Bouvier, C., Bettarel, Y., Bouvier, T., 2015. High diversity of skin-associated bacterial communities of marine fishes is promoted by their high variability among body parts, individuals and species. FEMS Microbiol. Ecol. 91, 1-12. https://doi.org/10.1093/femsec/fiv061

Davis, N.M., Proctor, D.M., Holmes, S.P., Relman, D.A., Callahan, B.J., 2018. Simple statistical identification and removal of contaminant sequences in marker-gene and metagenomics data. Microbiome 6, 226. https://doi.org/10.1186/s40168-018-0605-2

del Campo, J., Bass, D., Keeling, P.J., 2019. The eukaryome: Diversity and role of microeukaryotic organisms associated with animal hosts. Funct. Ecol. 1-10. https://doi.org/10.1111/1365-2435.13490

Delamare-Deboutteville, J., Khor, L., Chadag, V., 2021. Quick fish sampling guide for disease diagnostics - Microbiome sampling guide. WorldFish.

Deng, Y., Zhou, F., Ruan, Y., Ma, B., Ding, X., Yue, X., Ma, W., Yin, X., 2019. Feed Types 
683

684

685

686

687

688

689

690

691

692

693

694

695

696

697

698

699

700

701

702

703

704

705

706

707

708
Driven Differentiation of Microbial Community and Functionality in Marine Integrated Multitrophic Aquaculture System. Water 12, 95. https://doi.org/10.3390/w12010095 Dixon, P., 2003. VEGAN, a package of R functions for community ecology. J. Veg. Sci. 14, 927-930. https://doi.org/10.1111/j.1654-1103.2003.tb02228.x

Doane, M.P., Morris, M.M., Papudeshi, B., Allen, L., Pande, D., Haggerty, J.M., Johri, S., Turnlund, A.C., Peterson, M., Kacev, D., Nosal, A., Ramirez, D., Hovel, K., Ledbetter, J., Alker, A., Avalos, J., Baker, K., Bhide, S., Billings, E., Byrum, S., Clemens, M., Demery, A.J., Lima, L.F.O., Gomez, O., Gutierrez, O., Hinton, S., Kieu, D., Kim, A., Loaiza, R., Martinez, A., McGhee, J., Nguyen, K., Parlan, S., Pham, A., Price-Waldman, R., Edwards, R.A., Dinsdale, E.A., 2020. The skin microbiome of elasmobranchs follows phylosymbiosis, but in teleost fishes, the microbiomes converge. Microbiome 8, 93. https://doi.org/10.1186/s40168-020-00840-x

Dong, H.T., LaFrentz, B., Pirarat, N., Rodkhum, C., 2015. Phenotypic characterization and genetic diversity of Flavobacterium columnare isolated from red tilapia, Oreochromis sp., in Thailand. J. Fish Dis. 38, 901-913. https://doi.org/10.1111/jfd.12304

Dong, H.T., Techatanakitarnan, C., Jindakittikul, P., Thaiprayoon, A., Taengphu, S., Charoensapsri, W., Khunrae, P., Rattanarojpong, T., Senapin, S., 2017. Aeromonas jandaei and Aeromonas veronii caused disease and mortality in Nile tilapia, Oreochromis niloticus (L.). J. Fish Dis. 40, 1395-1403. https://doi.org/10.1111/jfd.12617

El-Dien, A.H.S., Abdel-Gaber, R.A., 2009. Ichthyophthirius multifiliis infection induces apoptosis in different species of Tilapia. J. Egypt. Soc. Parasitol. 39, 665-678.

El-Sayed, A.F.M., 2019. Tilapia Culture, 2nd ed. Academic Press.

Ellison, A.R., Uren Webster, T.M., Rey, O., Garcia de Leaniz, C., Consuegra, S., OrozcoterWengel, P., Cable, J., 2018. Transcriptomic response to parasite infection in Nile tilapia (Oreochromis niloticus) depends on rearing density. BMC Genomics 19, 723. https://doi.org/10.1186/s12864-018-5098-7

Ellison, A.R., Wilcockson, D., Cable, J., 2021. (Accepted/In press). Circadian dynamics of the teleost skin immune-microbiome interface. Microbiome. https://doi.org/10.1101/2021.01.29.428758

Elsaied, H.E., Soliman, T., Abu-Taleb, H.T., Goto, H., Jenke-Kodam, H., 2019. Phylogenetic characterization of eukaryotic and prokaryotic gut flora of Nile tilapia, Oreochromis niloticus, along niches of Lake Nasser, Egypt, based on rRNA gene high-throughput sequences. Ecol. Genet. Genomics 11, 100037. https://doi.org/10.1016/j.egg.2019.100037

Fan, L.M., Barry, K., Hu, G.D., Meng, S. long, Song, C., Wu, W., Chen, J.Z., Xu, P., 2016. Bacterioplankton community analysis in tilapia ponds by Illumina high-throughput sequencing. World J. Microbiol. Biotechnol. 32, 10. https://doi.org/10.1007/s11274-0151962-7

Food and Agriculture Organization of the United Nations (FAO), 2020a. The State of World Fisheries and Aquaculture 2020. Sustainability in Action. Rome.

https://doi.org/10.4060/ca9229en

Food and Agriculture Organization of the United Nations (FAO), 2020b. Fishery and Aquaculture Statistics. Global aquaculture production 1950-2018 (FishStatJ) [WWW Document]. FAO Fish. Aquac. Dep. URL www.fao.org/fishery/statistics/software/fishstatj/en

Food and Agriculture Organization of the United Nations (FAO), 2020c. Cultured Aquatic Species Information Programme Oreochromis niloticus (Linnaeus, 1758) [WWW Document]. URL http://www.fao.org/fishery/cultured species/Oreochromis_niloticus/en (accessed 7.16.20). 
Foster, Z.S.L., Sharpton, T.J., Grünwald, N.J., 2017. Metacoder: An R package for visualization and manipulation of community taxonomic diversity data. PLOS Comput. Biol. 13, e1005404. https://doi.org/10.1371/journal.pcbi.1005404

Fuentes, J., Garbayo, I., Cuaresma, M., Montero, Z., González-del-Valle, M., Vílchez, C., 2016. Impact of Microalgae-Bacteria Interactions on the Production of Algal Biomass and Associated Compounds. Mar. Drugs 14, 100. https://doi.org/10.3390/md14050100

Gadoin, E., Desnues, C., Monteil-Bouchard, S., Bouvier, T., Auguet, J.-C., Roque d'Orbcastel, E., Bettarel, Y., 2021. Fishing for the Virome of Tropical Tuna. Viruses 13, 1291. https://doi.org/10.3390/v13071291

Gomez, J.A., Primm, T.P., 2021. A Slimy Business: the Future of Fish Skin Microbiome Studies. Microb. Ecol. https://doi.org/10.1007/s00248-020-01648-w

Guedes, A.C., Malcata, F.X., 2012. Nutritional Value and Uses of Microalgae in Aquaculture, in: Muchlisin, Z. (Ed.), Aquaculture. IntechOpen. https://doi.org/10.5772/30576

Guillou, L., Bachar, D., Audic, S., Bass, D., Berney, C., Bittner, L., Boutte, C., Burgaud, G., de Vargas, C., Decelle, J., del Campo, J., Dolan, J.R., Dunthorn, M., Edvardsen, B., Holzmann, M., Kooistra, W.H.C.F., Lara, E., Le Bescot, N., Logares, R., Mahé, F., Massana, R., Montresor, M., Morard, R., Not, F., Pawlowski, J., Probert, I., Sauvadet, A.-L., Siano, R., Stoeck, T., Vaulot, D., Zimmermann, P., Christen, R., 2012. The Protist Ribosomal Reference database (PR2): a catalog of unicellular eukaryote Small Sub-Unit rRNA sequences with curated taxonomy. Nucleic Acids Res. 41, D597-D604. https://doi.org/10.1093/nar/gks1160

Hal, A.M., El-Barbary, M.I., 2020. Gene expression and histopathological changes of Nile tilapia (Oreochromis niloticus) infected with Aeromonas hydrophila and Pseudomonas fluorescens. Aquaculture 526, 735392. https://doi.org/10.1016/j.aquaculture.2020.735392

Henchion, M., Hayes, M., Mullen, A., Fenelon, M., Tiwari, B., 2017. Future Protein Supply and Demand: Strategies and Factors Influencing a Sustainable Equilibrium. Foods 6, 53. https://doi.org/10.3390/foods6070053

Hinchliffe, S., Butcher, A., Rahman, M.M., Guilder, J., Tyler, C., Verner-Jeffreys, D., 2020. Production without medicalisation - risk practices and disease in Bangladesh aquaculture. Geogr. J. geoj.12371. https://doi.org/10.1111/geoj.12371

Kanther, M., Tomkovich, S., Xiaolun, S., Grosser, M.R., Koo, J., Flynn, E.J., Jobin, C., Rawls, J.F., 2014. Commensal microbiota stimulate systemic neutrophil migration through induction of Serum amyloid A. Cell. Microbiol. 16, 1053-1067. https://doi.org/10.1111/cmi.12257

Kelly, C., Salinas, I., 2017. Under Pressure: Interactions between Commensal Microbiota and the Teleost Immune System. Front. Immunol. 8. https://doi.org/10.3389/fimmu.2017.00559

Kim, P.S., Shin, N.-R., Lee, J.-B., Kim, M.-S., Whon, T.W., Hyun, D.-W., Yun, J.-H., Jung, M.-J., Kim, J.Y., Bae, J.-W., 2021. Host habitat is the major determinant of the gut microbiome of fish. Microbiome 9, 166. https://doi.org/10.1186/s40168-021-01113-x

Krotman, Y., Yergaliyev, T.M., Alexander Shani, R., Avrahami, Y., Szitenberg, A., 2020. Dissecting the factors shaping fish skin microbiomes in a heterogeneous inland water system. Microbiome 8, 1-15. https://doi.org/10.1186/s40168-020-0784-5

Kuznetsova, A., Brockhoff, P.B., Christensen, R.H.B., 2017. lmerTest Package: Tests in Linear Mixed Effects Models. J. Stat. Softw. 82. https://doi.org/10.18637/jss.v082.i13 Laforest-Lapointe, I., Arrieta, M.-C., 2018. Microbial Eukaryotes: a Missing Link in Gut Microbiome Studies. mSystems 3. https://doi.org/10.1128/mSystems.00201-17 Lahti, L., Shetty, S., 2017. Tools for microbiome anaysis in R. 
Lane, D.J., 1991. 16S/23S sequencing, in: Stackerbrant, E., Goodfellow, M. (Eds.), Nucleic Acid Techniques. Wiley, New York, pp. 115-175.

Lear, G., Bellamy, J., Case, B.S., Lee, J.E., Buckley, H.L., 2014. Fine-scale spatial patterns in bacterial community composition and function within freshwater ponds. ISME J. 8, 1715-1726. https://doi.org/10.1038/ismej.2014.21

Lee, J.E., Buckley, H.L., Etienne, R.S., Lear, G., 2013. Both species sorting and neutral processes drive assembly of bacterial communities in aquatic microcosms. FEMS Microbiol. Ecol. 86, 288-302. https://doi.org/10.1111/1574-6941.12161

Legrand, T.P.R.A., Catalano, S.R., Wos-Oxley, M.L., Stephens, F., Landos, M., Bansemer, M.S., Stone, D.A.J., Qin, J.G., Oxley, A.P.A., 2018. The inner workings of the outer surface: Skin and gill microbiota as indicators of changing gut health in Yellowtail Kingfish. Front. Microbiol. 8, 1-17. https://doi.org/10.3389/fmicb.2017.02664

Lever, M.A., Torti, A., Eickenbusch, P., Michaud, A.B., Šantl-Temkiv, T., Jørgensen, B.B., 2015. A modular method for the extraction of DNA and RNA, and the separation of DNA pools from diverse environmental sample types. Front. Microbiol. 6. https://doi.org/10.3389/fmicb.2015.00476

Li, X., Marella, T.K., Tao, L., Peng, L., Song, C., Dai, L., Tiwari, A., Li, G., 2017. A novel growth method for diatom algae in aquaculture waste water for natural food development and nutrient removal. Water Sci. Technol. 75, 2777-2783. https://doi.org/10.2166/wst.2017.156

Limbu, S.M., Zhou, L., Sun, S.X., Zhang, M.L., Du, Z.Y., 2018. Chronic exposure to low environmental concentrations and legal aquaculture doses of antibiotics cause systemic adverse effects in Nile tilapia and provoke differential human health risk. Environ. Int. 115, 205-219. https://doi.org/10.1016/j.envint.2018.03.034

Link, J.S., Watson, R.A., 2019. Global ecosystem overfishing: Clear delineation within real limits to production. Sci. Adv. 5, eaav0474. https://doi.org/10.1126/sciadv.aav0474

Liu, H., Guo, X., Gooneratne, R., Lai, R., Zeng, C., Zhan, F., Wang, W., 2016. The gut microbiome and degradation enzyme activity of wild freshwater fishes influenced by their trophic levels. Sci. Rep. 6, 1-12. https://doi.org/10.1038/srep24340

Liu, Z., Ke, X., Lu, M., Gao, F., Cao, J., Zhu, H., Wang, M., 2015. Identification and pathological observation of a pathogenic Plesiomonas shigelloides strain isolated from cultured tilapia (Oreochromis niloticus). Wei Sheng Wu Xue Bao 55, 96-106.

Llewellyn, M.S., Leadbeater, S., Garcia, C., Sylvain, F.E., Custodio, M., Ang, K.P., Powell, F., Carvalho, G.R., Creer, S., Elliot, J., Derome, N., 2017. Parasitism perturbs the mucosal microbiome of Atlantic Salmon. Sci. Rep. 7, 1-10. https://doi.org/10.1038/srep43465

Malick, R.C., Bera, A.K., Chowdhury, H., Bhattacharya, M., Abdulla, T., Swain, H.S., Baitha, R., Kumar, V., Das, B.K., 2020. Identification and pathogenicity study of emerging fish pathogens Acinetobacter junii and Acinetobacter pittii recovered from a disease outbreak in Labeo catla (Hamilton, 1822) and Hypophthalmichthys molitrix (Valenciennes, 1844) of freshwater wetland in. Aquac. Res. 51, 2410-2420. https://doi.org/10.1111/are.14584

Marmen, S., Aharonovich, D., Grossowicz, M., Blank, L., Yacobi, Y.Z., Sher, D.J., 2016. Distribution and Habitat Specificity of Potentially-Toxic Microcystis across Climate, Land, and Water Use Gradients. Front. Microbiol. 7. https://doi.org/10.3389/fmicb.2016.00271

Marmen, S., Fadeev, E., Al Ashhab, A., Benet-Perelberg, A., Naor, A., Patil, H.J., Cytryn, E., Viner-Mozzini, Y., Sukenik, A., Lalzar, M., Sher, D., 2021. Seasonal Dynamics Are the Major Driver of Microbial Diversity and Composition in Intensive Freshwater Aquaculture. Front. Microbiol. 12. https://doi.org/10.3389/fmicb.2021.679743 
Martin, B.D., Witten, D., Willis, A.D., 2020. Modeling microbial abundances and dysbiosis with beta-binomial regression. Ann. Appl. Stat. 14, 94-115. https://doi.org/10.1214/19AOAS1283

McMurdie, P.J., Holmes, S., 2013. phyloseq: An R Package for Reproducible Interactive Analysis and Graphics of Microbiome Census Data. PLoS One 8, e61217.

Medlin, L., Elwood, H.J., Stickel, S., Sogin, M.L., 1988. The characterization of enzymatically amplified eukaryotic 16S-like rRNA-coding regions. Gene 71, 491-499. https://doi.org/10.1016/0378-1119(88)90066-2

Minich, J.J., Zhu, Q., Xu, Z.Z., Amir, A., Ngochera, M., Simwaka, M., Allen, E.E., Zidana, H., Knight, R., 2018. Microbial effects of livestock manure fertilization on freshwater aquaculture ponds rearing tilapia (Oreochromis shiranus) and North African catfish (Clarias gariepinus). Microbiologyopen 7, 1-15. https://doi.org/10.1002/mbo3.716

Minniti, G., Hagen, L.H., Porcellato, D., Jørgensen, S.M., Pope, P.B., Vaaje-Kolstad, G., 2017. The skin-mucus microbial community of farmed Atlantic salmon (Salmo salar). Front. Microbiol. 8, 1-11. https://doi.org/10.3389/fmicb.2017.02043

Mohammed, H.H., Arias, C.R., 2015. Potassium permanganate elicits a shift of the external fish microbiome and increases host susceptibility to columnaris disease. Vet. Res. 46, 113. https://doi.org/10.1186/s13567-015-0215-y

Murray, A.G., Peeler, E.J., 2005. A framework for understanding the potential for emerging diseases in aquaculture. Prev. Vet. Med. 67, 223-235.

https://doi.org/10.1016/j.prevetmed.2004.10.012

Nhan, D.K., Verdegem, M.C.J., Milstein, A., Verreth, J.A. V, 2008. Water and nutrient budgets of ponds in integrated agriculture-aquaculture systems in the Mekong Delta, Vietnam. Aquac. Res. 39, 1216-1228. https://doi.org/10.1111/j.13652109.2008.01986.x

OIE, 2013. Infection with Aphanomyces invadans (Epizootic Ulcerative Syndrome), in: Manual of Diagnostic Tests for Aquatic Animals. World Organisation for Animal Health.

Palarea-Albaladejo, J., Martín-Fernández, J.A., 2015. zCompositions — R package for multivariate imputation of left-censored data under a compositional approach. Chemom. Intell. Lab. Syst. 143, 85-96. https://doi.org/10.1016/j.chemolab.2015.02.019

Parada, A.E., Needham, D.M., Fuhrman, J.A., 2016. Every base matters: assessing small subunit rRNA primers for marine microbiomes with mock communities, time series and global field samples. Environ. Microbiol. 18, 1403-1414. https://doi.org/10.1111/14622920.13023

Perry, W.B., Lindsay, E., Payne, C.J., Brodie, C., Kazlauskaite, R., 2020. The role of the gut microbiome in sustainable teleost aquaculture. Proc. R. Soc. B Biol. Sci. 287. https://doi.org/10.1098/rspb.2020.0184

Pulkkinen, K., Suomalainen, L.-R., Read, A.F., Ebert, D., Rintamäki, P., Valtonen, E.T., 2010. Intensive fish farming and the evolution of pathogen virulence: the case of columnaris disease in Finland. Proc. R. Soc. B Biol. Sci. 277, 593-600. https://doi.org/10.1098/rspb.2009.1659

Qin, Y., Hou, J., Deng, M., Liu, Q., Wu, C., Ji, Y., He, X., 2016. Bacterial abundance and diversity in pond water supplied with different feeds. Sci. Rep. 6, 35232. https://doi.org/10.1038/srep35232

Quast, C., Pruesse, E., Yilmaz, P., Gerken, J., Schweer, T., Yarza, P., Peplies, J., Glöckner, F.O., 2012. The SILVA ribosomal RNA gene database project: improved data processing and web-based tools. Nucleic Acids Res. 41, D590-D596. https://doi.org/10.1093/nar/gks 1219

Ramanan, R., Kim, B.-H., Cho, D.-H., Oh, H.-M., Kim, H.-S., 2016. Algae-bacteria 
886

887

888

889

890

891

892

893

894

895

896

897

898

899

900

901

902

903

904

905

906

907

908

909

910

911

912

913

914

915

916

917

918

919

interactions: Evolution, ecology and emerging applications. Biotechnol. Adv. 34, 14-29. https://doi.org/10.1016/j.biotechadv.2015.12.003

Reid, K.M., Patel, S., Robinson, A.J., Bu, L., Jarungsriapisit, J., Moore, L.J., Salinas, I., 2017. Salmonid alphavirus infection causes skin dysbiosis in Atlantic salmon (Salmo salar L.) post-smolts. PLoS One 12, 1-17. https://doi.org/10.1371/journal.pone.0172856

Reinhart, E.M., Korry, B.J., Rowan-Nash, A.D., Belenky, P., 2019. Defining the Distinct Skin and Gut Microbiomes of the Northern Pike (Esox lucius). Front. Microbiol. 10, 112. https://doi.org/10.3389/fmicb.2019.02118

Rogers, J.E., Devereux, R., James, J.B., George, S.E., Forshay, K.J., 2021. Seasonal Distribution of Cyanobacteria in Three Urban Eutrophic Lakes Results from an Epidemic-like Response to Environmental Conditions. Curr. Microbiol. 78, 2298-2316. https://doi.org/10.1007/s00284-021-02498-6

Rosado, D., Pérez-Losada, M., Pereira, A., Severino, R., Xavier, R., 2021. Effects of aging on the skin and gill microbiota of farmed seabass and seabream. Anim. Microbiome 3, 10. https://doi.org/10.1186/s42523-020-00072-2

Rosado, D., Pérez-Losada, M., Severino, R., Cable, J., Xavier, R., 2019a. Characterization of the skin and gill microbiomes of the farmed seabass (Dicentrarchus labrax) and seabream (Sparus aurata). Aquaculture 500, 57-64. https://doi.org/10.1016/j.aquaculture.2018.09.063

Rosado, D., Xavier, R., Severino, R., Tavares, F., Cable, J., Pérez-Losada, M., 2019b. Effects of disease, antibiotic treatment and recovery trajectory on the microbiome of farmed seabass (Dicentrarchus labrax). Sci. Rep. 9, 1-11. https://doi.org/10.1038/s41598-01955314-4

Schliep, K.P., 2010. phangorn: phylogenetic analysis in R. Bioinformatics 27, 592-593. https://doi.org/10.1093/bioinformatics/btq706

Sharpton, T.J., Stagaman, K., Sieler, M.J., Arnold, H.K., Davis, E.W., 2021. Phylogenetic Integration Reveals the Zebrafish Core Microbiome and Its Sensitivity to Environmental Exposures. Toxics 9, 10. https://doi.org/10.3390/toxics9010010

Sherr, E.B., Sherr, B.F., 2002. Significance of predation by protists in aquatic microbial food webs. Antonie Van Leeuwenhoek 81, 293-308.

https://doi.org/10.1023/A:1020591307260

Sundh, H., Finne-Fridell, F., Ellis, T., Taranger, G.L., Niklasson, L., Pettersen, E.F., Wergeland, H.I., Sundell, K., 2019. Reduced water quality associated with higher stocking density disturbs the intestinal barrier functions of Atlantic salmon (Salmo salar L.). Aquaculture 512, 734356. https://doi.org/10.1016/j.aquaculture.2019.734356

Suphoronski, S.A., Chideroli, R.T., Facimoto, C.T., Mainardi, R.M., Souza, F.P., LoperaBarrero, N.M., Jesus, G.F.A., Martins, M.L., Di Santis, G.W., de Oliveira, A., Gonçalves, G.S., Dari, R., Frouel, S., Pereira, U.P., 2019. Effects of a phytogenic, alone and associated with potassium diformate, on tilapia growth, immunity, gut microbiome and resistance against francisellosis. Sci. Rep. 9, 6045. https://doi.org/10.1038/s41598019-42480-8

Tan, H.Y., Chen, S.W., Hu, S.Y., 2019. Improvements in the growth performance, immunity, disease resistance, and gut microbiota by the probiotic Rummeliibacillus stabekisii in Nile tilapia (Oreochromis niloticus). Fish Shellfish Immunol. 92, 265-275. https://doi.org/10.1016/j.fsi.2019.06.027

Tarnecki, A.M., Brennan, N.P., Schloesser, R.W., Rhody, N.R., 2019. Shifts in the SkinAssociated Microbiota of Hatchery-Reared Common Snook Centropomus undecimalis During Acclimation to the Wild. Microb. Ecol. 77, 770-781. https://doi.org/10.1007/s00248-018-1252-7

Tsuchiya, C., Sakata, T., Sugita, H., 2007. Novel ecological niche of Cetobacterium somerae, 
an anaerobic bacterium in the intestinal tracts of freshwater fish. Lett. Appl. Microbiol. 071018031740002-??? https://doi.org/10.1111/j.1472-765X.2007.02258.x

Warnecke, F., Amann, R., Pernthaler, J., 2004. Actinobacterial 16S rRNA genes from freshwater habitats cluster in four distinct lineages. Environ. Microbiol. 6, 242-253. https://doi.org/10.1111/j.1462-2920.2004.00561.x

Webster, T.M.U., Consuegra, S., Hitchings, M., de Leaniz, C.G., 2018. Interpopulation variation in the Atlantic salmon microbiome reflects environmental and genetic diversity. Appl. Environ. Microbiol. 84, 1-14. https://doi.org/10.1128/AEM.000691-18

Wu, D.X., Zhao, S.M., Peng, N., Xu, C.P., Wang, J., Liang, Y.X., 2016. Effects of a probiotic (Bacillus subtilis FY99-01) on the bacterial community structure and composition of shrimp (Litopenaeus vannamei, Boone) culture water assessed by denaturing gradient gel electrophoresis and high-throughput sequencing. Aquac. Res. 47, 857-869. https://doi.org/10.1111/are.12545

Yang, C., Albright, L., 1992. Effects of the harmful diatom Chaetoceros concavicornis on respiration of rainbow trout Oncorhynchus mykiss. Dis. Aquat. Organ. 14, 105-114. https://doi.org/10.3354/dao014105

Zhang, Z., 2021. Research Advances on Tilapia Streptococcosis. Pathogens 10, 558. https://doi.org/10.3390/pathogens 10050558

Zhou, J., Ning, D., 2017. Stochastic Community Assembly: Does It Matter in Microbial Ecology? Microbiol. Mol. Biol. Rev. 81. https://doi.org/10.1128/MMBR.00002-17

Zhou, R., Wang, H., Wei, D., Zeng, S., Hou, D., Weng, S., He, J., Huang, Z., 2021. Bacterial and eukaryotic community interactions might contribute to shrimp culture pond soil ecosystem at different culture stages. Soil Ecol. Lett. https://doi.org/10.1007/s42832021-0082-6

Zimba, P. V, Grimm, C.C., 2003. A synoptic survey of musty/muddy odor metabolites and microcystin toxin occurrence and concentration in southeastern USA channel catfish (Ictalurus punctatus Ralfinesque) production ponds. Aquaculture 218, 81-87. https://doi.org/10.1016/S0044-8486(02)00519-7 
bioRxiv preprint doi: https://doi.org/10.1101/2021.12.06.470702; this version posted December 6, 2021. The copyright holder for this preprint (which was not certified by peer review) is the author/funder, who has granted bioRxiv a license to display the preprint in perpetuity. It is made available under aCC-BY-NC-ND 4.0 International license.
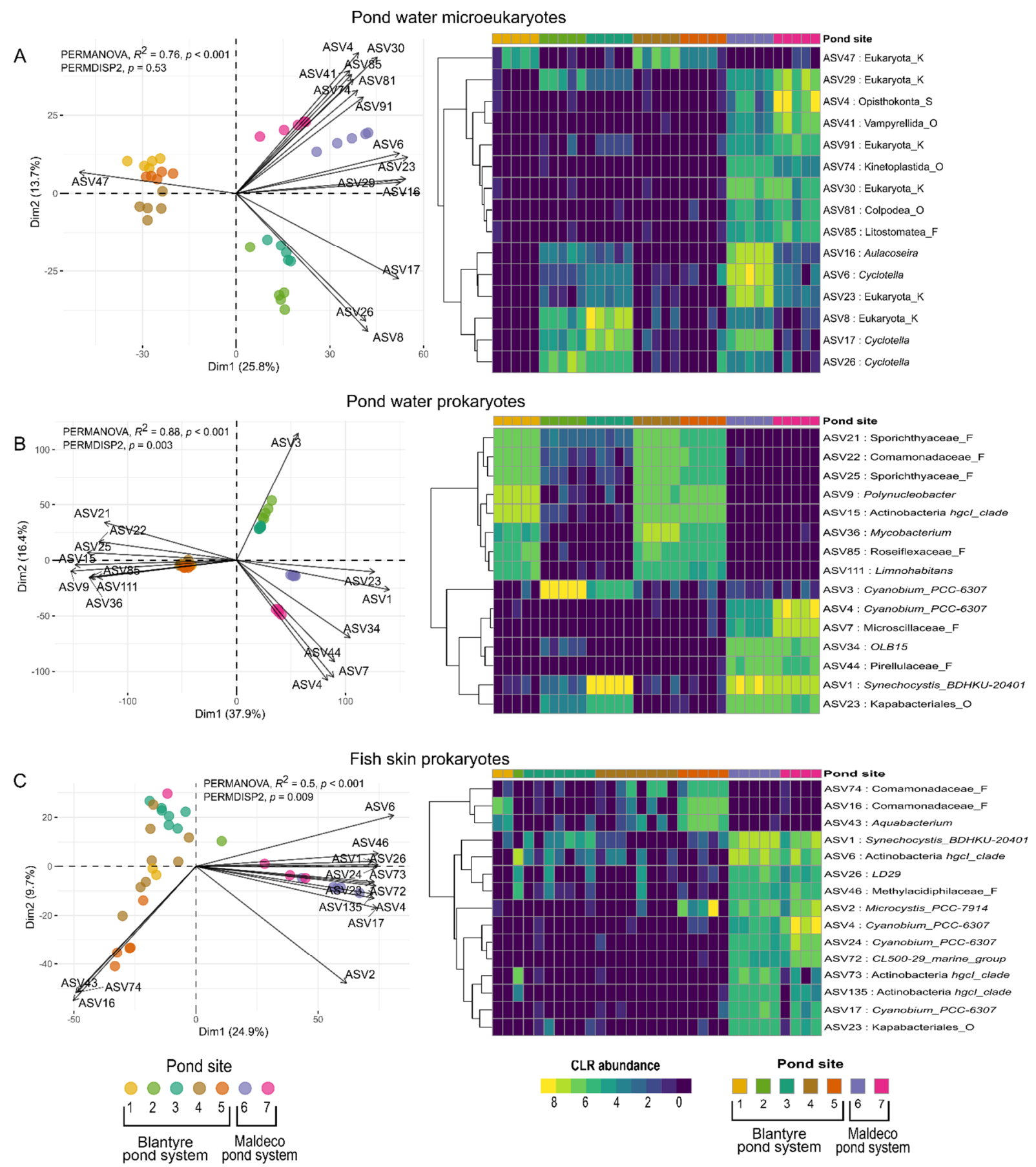

Figure 1: Microbial compositional diversity and abundance of pond water varies significantly by pond site, with trends for inter-site variation consistent across bacterial and eukaryotic communities. Fish skin samples show significant dispersion within pond sites. Left panel: ASVs were subjected to count zero multiplicative replacement prior to compositional transformation by centred log-ratios (CLR) and ordination by PCoA biplots on Euclidean distance of log-ratios (Aitchison distance). Points represent pond water samples, coloured by pond site, with arrows for top 15 ASVs explaining variation between samples. ASV abundances increase in the direction of arrows and arrow length represents magnitude of change. Angles between arrows denote correlation between ASVs (approximately $0^{\circ}=$ correlated, $<90^{\circ}$ positive correlation, $>90^{\circ}$ negative correlation, $90^{\circ}$ no correlation). Difference between pond sites was tested statistically by PERMANOVA, and dispersion within pond sites was determined by permutation tests for homogeneity of multivariate dispersions. Right panel: The CLR abundances of these 15 discriminant ASVs are plotted as accompanying heatmaps, with ASVs ordered according to a hierarchical clustering dendrogram. Labels include ASV number, lowest available taxonomic classification and rank of this classification e.g. “_F” = Family. 
962
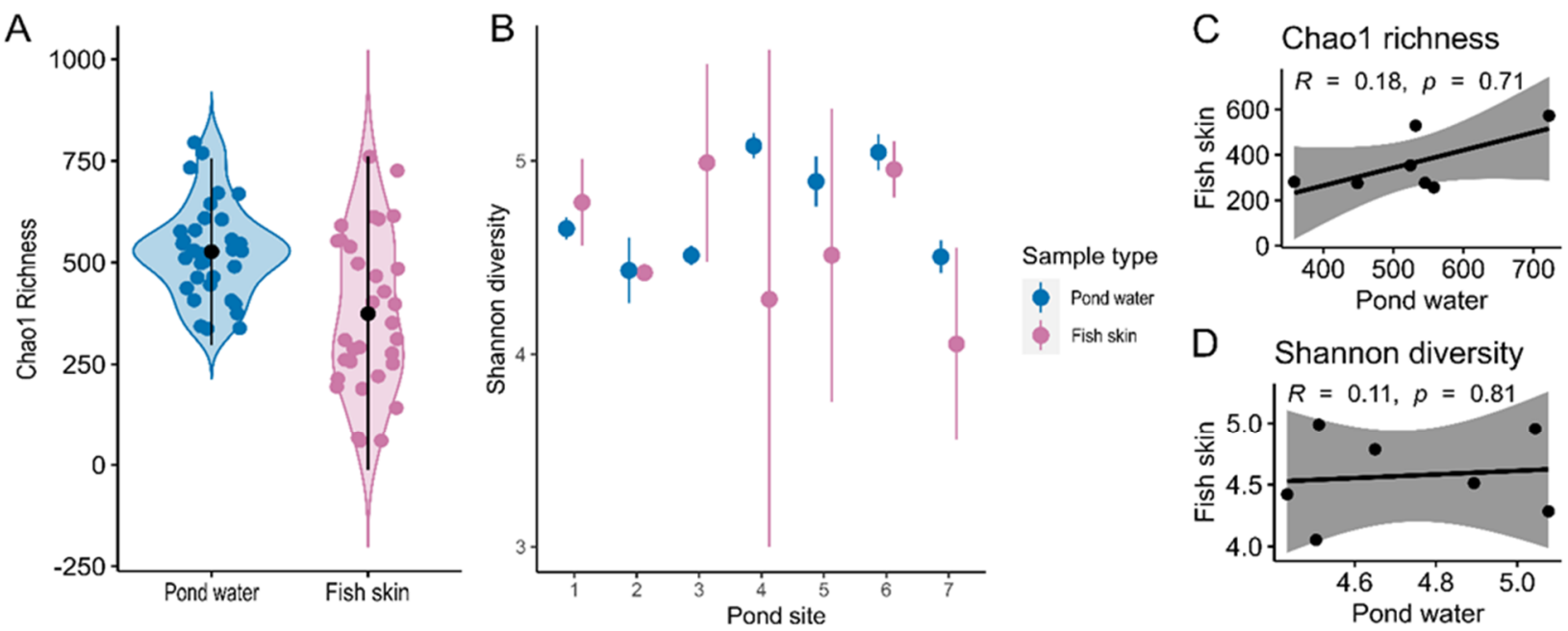

Pond water

Fish skin

D Shannon diversity
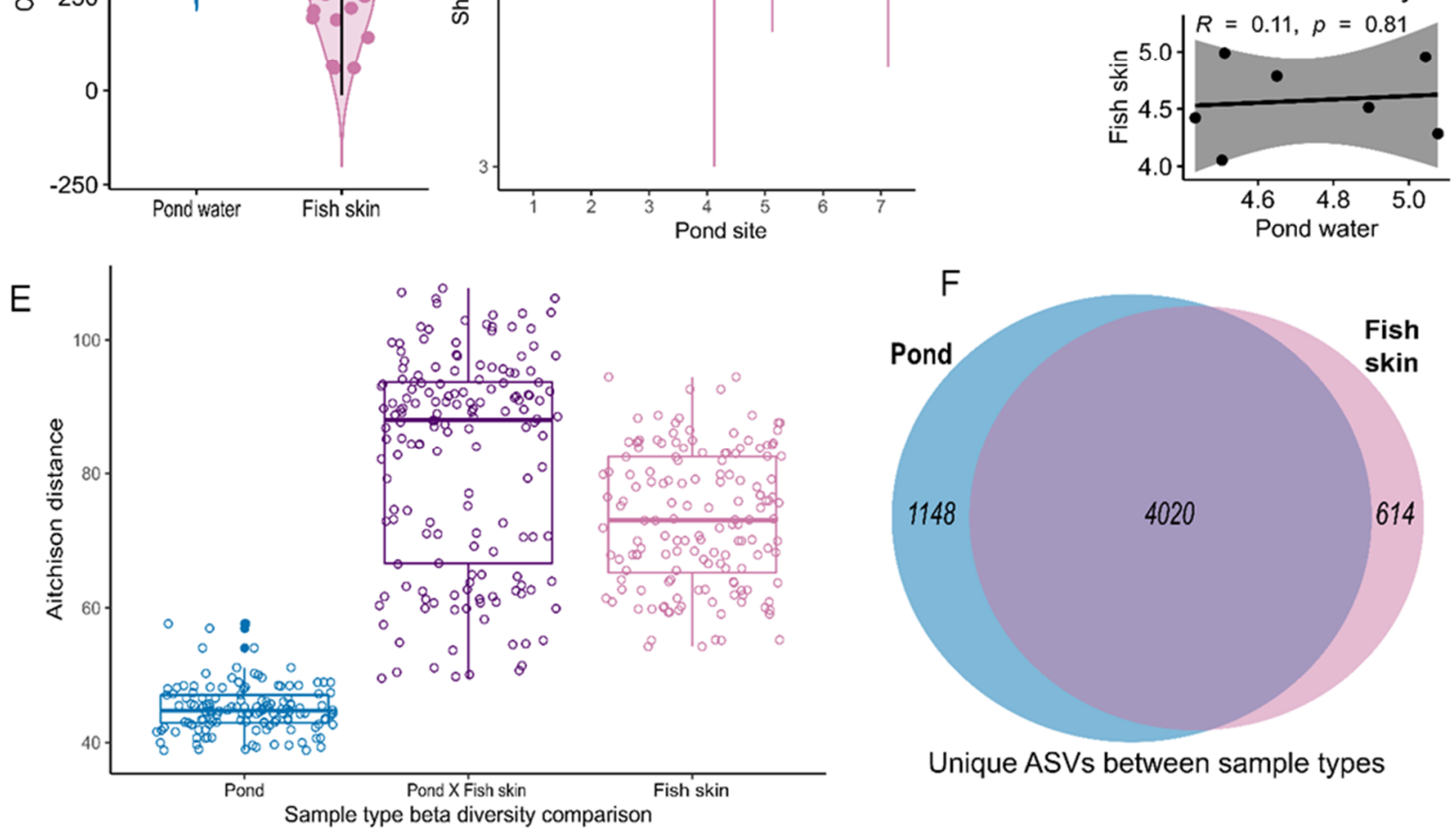

Unique ASVs between sample types

Figure 2: Comparisons of prokaryotic richness and diversity between pond water and fish skin.

A. Chao1 richness estimates of ASVs per sample, with sample type group means and standard deviations. Linear mixed effects modelling, accounting for pond site as a random effect, predicted fish skin to be significantly less rich than pond water by $503 \pm 59.49$ ASVs $\left(R^{2} \mathrm{c}=0.61, p<0.001\right)$. B. Shannon diversity was calculated for each sample and plotted for each pond site as group means and standard deviations. The same linear mixed effects model as above found Shannon diversity did not significantly differ between pond water $4.96 \pm 0.12$ and fish skin $4.72 \pm 0.15\left(R^{2} \mathrm{c}=0.11, p=0.115\right)$. C, D. Chao1 richness and Shannon diversity showed no correlation between fish skin and pond water, with points plotted for the mean of each pond site. A regression line of Pearson's correlation coefficient is plotted, with $95 \%$ confidence intervals. E. Beta diversity pairwise comparisons of Aitchison distance between samples of pond water, pond water vs fish skin and fish skin, within each pond site. F. Number of ASVs unique or shared between pond water and fish skin. 

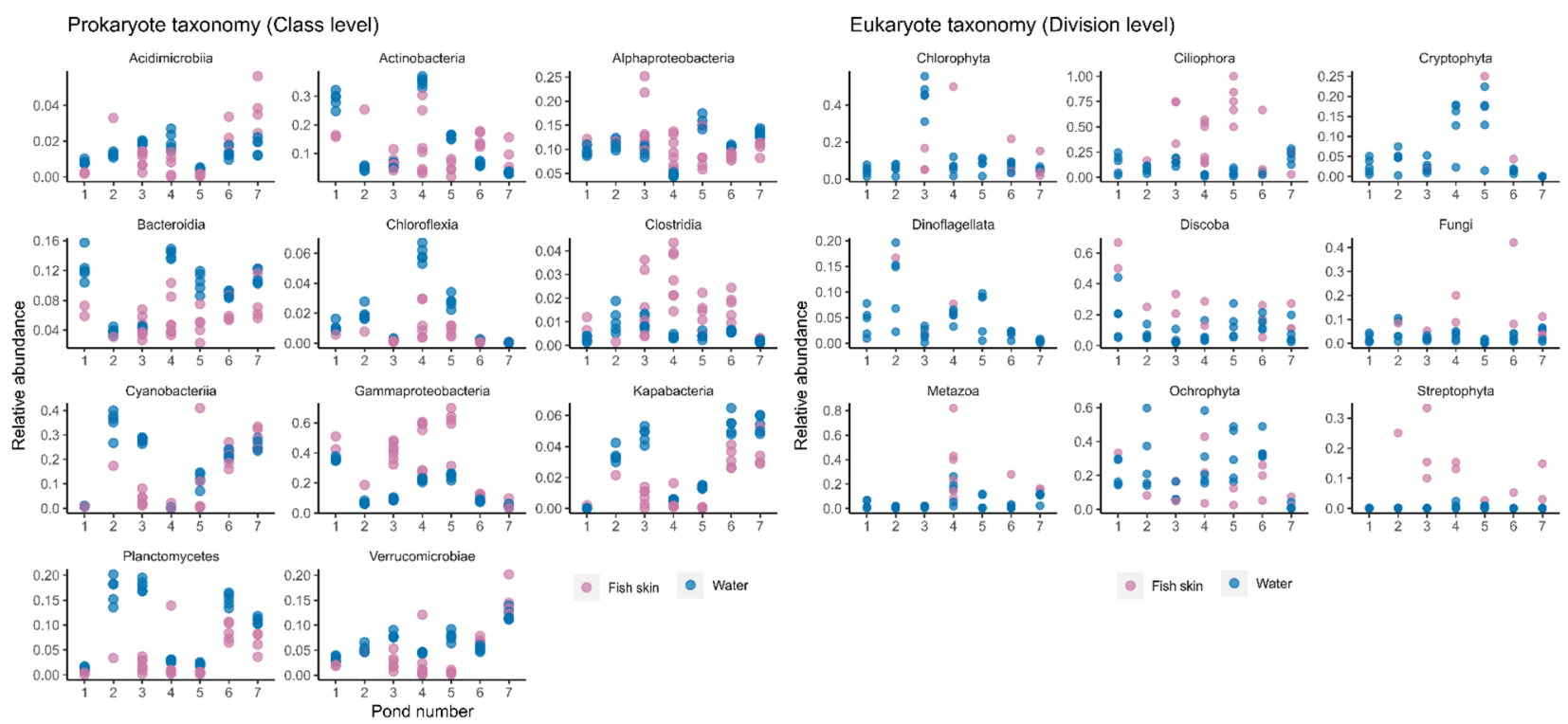

977

978

979

980

981

982

983

Figure 3: Relative abundance of bacterial (16S) and eukaryotic (18S) taxonomic communities. Each plot reveals the relative abundance for every sample collected at pond sites 1-7, with faceting at the taxonomic levels class (16S) and division (18S). Fish skin and pond water samples are represented in pink and blue respectively. Each facet is scaled independently.

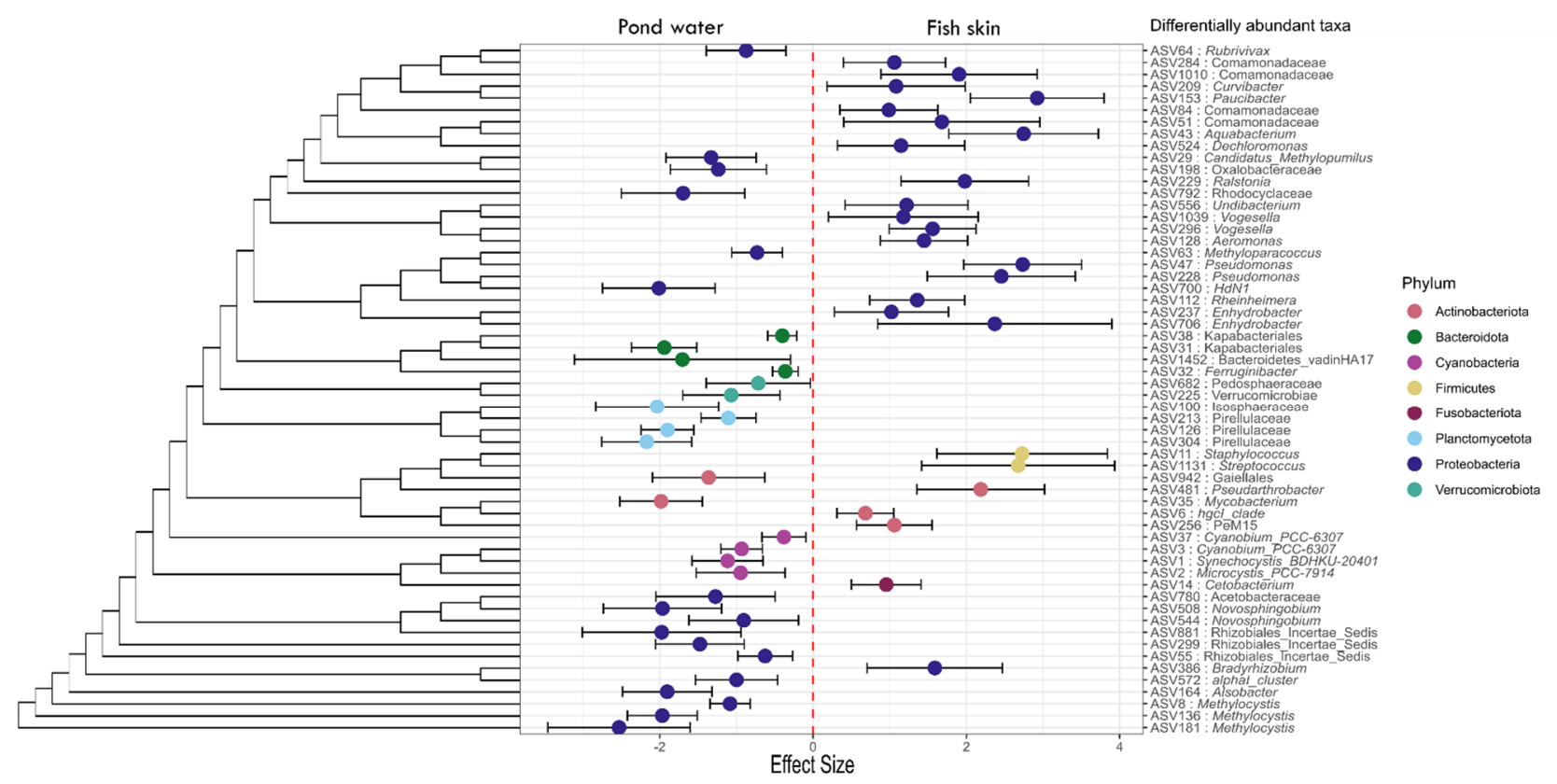

Figure 4: Differentially abundant prokaryotes of pond water and fish skin show phylogenetically conserved trends. Differential abundance of prokaryotic ASVs between pond water and fish skin sample types was modelled by beta-binomial regression model which accounted for pond site as a random effect. The effect sizes and 95\% prediction intervals of significant taxa (FDR <0.05) are plotted. Taxa to the left with a negative effect size are enriched in pond water, while taxa with a positive effect size are enriched in the fish skin. Taxa are ordered according to the phylogenetic tree, with labels include for the highest available taxonomic classification of each ASV. 
bioRxiv preprint doi: https://doi.org/10.1101/2021.12.06.470702; this version posted December 6, 2021. The copyright holder for this preprint (which was not certified by peer review) is the author/funder, who has granted bioRxiv a license to display the preprint in perpetuity. It is made available under aCC-BY-NC-ND 4.0 International license.
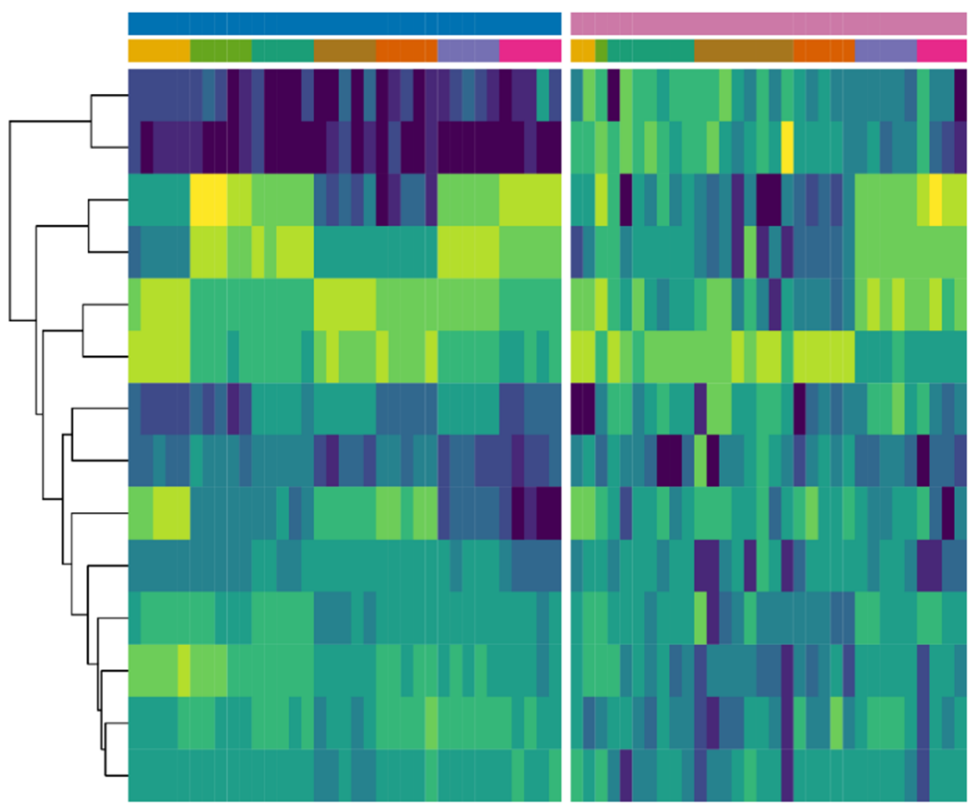
Sample type
Pond site

ASV47 : Pseudomonas

ASV8731: Sphingomonas

ASV3 : Cyanobium_PCC-6307

ASV44 : Pirellulaceae_F

ASV6 : hgcl_clade

ASV16: Comamonadaceae F

Figure 5: Core bacterial genera of tilapia skin communities. ASVs were amalgamated at genus

994 level, rarefied and core genera were classified across fish samples at an $80 \%$ prevalence threshold and $0.01 \%$ detection threshold. Abundance counts of core genera were transformed and are presented as non-rarefied compositional log ratios for both pond water and fish skin samples. Abundances were utilised for ordering by a hierarchical clustering dendrogram. 